\title{
Action of a cationic surfactant on the activity and removal of bacterial biofilms formed under different flow regimes
}

\author{
Manuel Simões, Maria Olivia Pereira, Maria João Vieira* \\ Department of Biological Engineering, Centro de Engenharia Biológica-IBQF, Universidade do Minho, Campus de Gualtar, \\ Gualtar, 4710-057 Braga, Portugal
}

Received 3 June 2004; received in revised form 10 September 2004; accepted 21 September 2004

\begin{abstract}
The action of the cationic surfactant cetyltrimethylammonium bromide (CTAB) was investigated to control biofilms (aged $7 \mathrm{~d}$ ) formed by Pseudomonas fluorescens on stainless-steel slides, using flow cells reactors, under turbulent and laminar flow. The effect of CTAB was also investigated using planktonic cells in the presence and absence of BSA, by measuring the cellular respiratory activity and the ATP released. The action of CTAB on biofilms was assessed by means of cellular respiratory activity and variation of biofilm mass, immediately and 3,7 and $12 \mathrm{~h}$ after the application of CTAB. The physical stability of the biofilm was also assessed using a rotating device, where the effect of the surfactant on the biofilm stability was evaluated through the variation of the mass remaining on the surface.

CTAB significantly reduced the activity of the planktonic cells probably due to the rupture of the cells. This effect was significantly reduced in the presence of BSA. Planktonic cells were more easily inactivated than bacteria in biofilms. Biofilms formed under laminar flow were more susceptible than those formed under turbulent flow, but in both cases total inactivation was not achieved. Biofilm recovery was observed, in terms of respiratory activity, in almost all the cases studied. CTAB application by itself did not promote the detachment of biofilms. The physical stability tests showed that the synergistic action of the surfactant and the application of high shear stress to the biofilm increase its detachment.
\end{abstract}

(C) 2004 Elsevier Ltd. All rights reserved.

Keywords: Biofilm control; Biofilm recovery; Flow regime; Physical stability; CTAB

\section{Introduction}

Bacterial attachment to surfaces and consequent biofilm formation are known phenomena in a diverse of environments such as marine, freshwater, medical, food and other industrial systems (Gibson et al., 1999). Biocides and disinfectants are one of the main means of controlling problems associated with microbial biofilm

\footnotetext{
*Corresponding author. Tel.: +351253604404; fax: +351253678986.

E-mail address: mjv@deb.uminho.pt (M.J. Vieira).
}

formation (Chen and Stewart, 2000), since mechanical cleaning is often impracticable and costly due to technical difficulties and equipment down time.

Quaternary ammonium compounds (QACs) are employed both as disinfectants for manual processing lines and surfaces in the food industry, and in human medicine area (Mereghetti et al., 2000), because of their excellent hard-surface cleaning, deodourization and antimicrobial properties (McDonnell and Russell, 1999). QAC's mode of action is attributed to their positive charge, which forms an electrostatic bond with negatively charged sites on microbial cell walls 
(McDonnell and Russell, 1999). Those electrostatic bonds create stresses in the wall, leading to cell lysis and death. QACs also cause cell death by protein denaturation, disruption of cell-wall permeability and reduction of the normal intake of life-sustaining nutrients to the cell (Cloëte et al., 1997). Cetyltrimethylammonium bromide (CTAB) is a QAC that appears to rupture the cell membrane. The primary site of action of CTAB has been suggested to be the lipid components of the membrane, causing cell lysis as secondary effect (Gilbert et al., 2002).

The purpose of this work was to assess the efficacy of CTAB in the control of biofilms of Pseudomonas fluorescens formed under both turbulent and laminar flow. For comparison purposes, tests with suspended cells, in the presence and absence of BSA were also carried out.

\section{Materials and methods}

\subsection{Microorganism and cell growth}

P. fluorescens (ATCC $13525^{\mathrm{T}}$ ) was used through this work. These bacteria are good biofilm producers and a major microorganism in biofilms found in industry (Pereira and Vieira, 2001). The growth conditions were $27^{\circ} \mathrm{C}, \mathrm{pH} 7$, and glucose as the carbon source.

The bacterial culture was grown in a chemostat, kept in a 0.51 glass reactor, aerated and agitated, and continuously fed with a sterile concentrated nutrient solution $(10 \mathrm{ml} / \mathrm{h})$ consisting of $5 \mathrm{~g}$ glucose $/ 1,2.5 \mathrm{~g}$ peptone $/ 1$ and $1.25 \mathrm{~g}$ yeast extract $/ 1$, in phosphate buffer (PB) at $\mathrm{pH}$ 7. This culture was used to continuously inoculate a 3.51 reactor, also aerated and agitated. This last reactor was fed with a minimal nutrients medium $(0.05 \mathrm{~g}$ glucose $/ 1,0.025 \mathrm{~g}$ peptone $/ 1$ and $0.0125 \mathrm{~g}$ yeast extract/1) in $\mathrm{PB}, \mathrm{pH} 7$, at a flow rate of $1.71 / \mathrm{h}$. The bacterial suspension was pumped up, passing through the flow cell reactors described elsewhere (Pereira et al., 2002a) and back to the 3.51 reactor.

\subsection{Surfactant}

The cationic surfactant CTAB, purchased from Merck (Cat. No. 102342; Critical micellar concentration- $-1.00 \mathrm{mM}$ ), was used throughout this work. The concentrations tested were $0.125,0.250,0.500$ and $0.900 \mathrm{mM}$, obtained by preparation with sterile distilled water.

\subsection{Surfactant neutralization}

Independent neutralization tests were carried out in order to choose the appropriate concentration and neutralizer of CTAB when applied to $P$. fluorescens.
The selected neutralization solution was prepared with the following reactants $(\mathrm{wt} / \mathrm{v}): 0.1 \%$ peptone, $0.5 \%$ Tween 80 and $0.07 \%$ lecithin, in $\mathrm{PB}, \mathrm{pH}$ 7. A concentrated neutralization solution was prepared and autoclaved prior to utilization. The neutralization reaction was allowed to proceed for $10 \mathrm{~min}$.

\subsection{Planktonic tests}

A culture $(200 \mathrm{ml})$ was harvested from the 0.51 chemostat, washed with saline PB $(\mathrm{pH} 7,0.01 \mathrm{M})$ by three consecutive steps of centrifugation $(3777 \mathrm{~g}, 5 \mathrm{~min})$, and resuspended in $\mathrm{PB}, \mathrm{pH} 7$, in order to obtain a final bacterial suspension with an OD of $0.4(\lambda=640 \mathrm{~nm}$, which corresponds to $\sim 1 \times 10^{9}$ cells $/ \mathrm{ml}$, with $\mathrm{PB}$ as blank). The bacterial culture was then divided by several sterilized glass flasks exposed to each concentration of the surfactant and placed in an orbital shaker $(120 \mathrm{rpm}$, $27^{\circ} \mathrm{C}$ ). After $30 \mathrm{~min}$ of contact with CTAB, the ATP released into the medium was determined (the presence of surfactant does not interfere with the ATP measurement - data not shown). Afterwards, the surfactant was neutralized, the bacterial suspension was carefully washed twice with saline PB and resuspended in $10 \mathrm{ml}$ of $\mathrm{PB}$ and the bacterial respiratory activity was assessed through oxygen consumption rates.

The mass of bacteria present in each flask was estimated by the determination of the total volatile solids (TVS) of bacterial cultures, according to standard methods (APHA, AWWA, WPCF, 1989).

To investigate the possible influence of the proteins on CTAB efficacy, the procedure described above was followed but with the previous addition of $3 \mathrm{~g} / 1$ of bovine serum albumin-BSA (Merck 12018) to the bacterial suspension, according to the European Standard-EN 1276 (1997), in order to simulate a dirty condition in industrial systems. The CTAB effect was assessed also by determining the bacterial respiratory activity.

\subsection{Experiments with biofilms-biofilm system}

A continuous flow cell reactor, described by Pereira et al. (2002a) and used by Simões et al. (2003a) to assess biocide efficacy on biofilms, was used for biofilm formation by $P$. fluorescens. It consists of a semi-circular PMMA duct with several apertures on its flat face to fit several coupons where biofilm formation surfaces $(1.75 \mathrm{~cm} \times 1.25 \mathrm{~cm})$ were glued. These surfaces were ASI 316 stainless-steel (SS) slides.

Biofilms were formed by recirculating the bacterial suspension, obtained from the 3.51 reactor at $27^{\circ} \mathrm{C}$ and $\mathrm{pH} 7$, through two similar flow cell reactors operating in parallel, each one with 10 slides for biofilm sampling. One of the flow cells was used to promote laminar flow $(R e=2000, \quad u=0.204 \mathrm{~m} / \mathrm{s})$ and the 
other turbulent flow $(R e=5200, u=0.532 \mathrm{~m} / \mathrm{s})$. The biofilms were allowed to grow for $7 \mathrm{~d}$ to ensure that steady-state biofilms were used in every experiment (Pereira et al. 2002a).

\subsection{Experiments with biofilms-biofilm tests}

The biofilms formed on the slides of each flow cell reactor were exposed to CTAB for $30 \mathrm{~min}$. Each CTAB concentration was tested in an independent experiment and each experiment was performed on three separate occasions. During the treatment period, the CTAB solution replaced the diluted bacterial suspension flowing in the flow cells. After the exposure to CTAB, the flow of this solution through the system was stopped and the bacterial suspension was re-introduced in order to restore the conditions prior to surfactant application to mimic real industrial situations. In each experiment, prior to the surfactant treatment, two metal slides of each flow cell were sampled and used as a control. Immediately after the surfactant treatment, two metal slides of each flow cell were sampled (time zero). The biofilms that covered the SS slides were completely scraped (as verified after microscopic visualization using DAPI staining-results not shown), resuspended in $10 \mathrm{ml}$ of neutralization solution and left for $10 \mathrm{~min}$. Then, the biofilms suspensions were vortexed for $30 \mathrm{~s}$ with $100 \%$ input, washed twice with saline $\mathrm{PB}$, resupended in $\mathrm{PB}$ and used immediately to assess the bacterial activity of the biofilm. Afterwards, the suspension was used to determine the biofilm mass. In order to assess whether time plays a significant role in the action of CTAB, namely if it prevents subsequent growth of the biofilm, the remaining slides were left in the flow cells and were sampled 3, 7 and $12 \mathrm{~h}$ after surfactant application. For every condition tested, two SS slides were sampled.

\subsection{Analytical methods-biofilm mass}

The dry mass of the biofilm accumulated on the slides was assessed by the determination of TVS of the homogenized biofilm suspensions, according to standard methods (APHA, AWWA, WPCF, 1989), method number $2540 \mathrm{~A}-\mathrm{D}$. The biofilm mass accumulated was expressed in $\mathrm{mg}$ of biofilm per $\mathrm{cm}^{2}$ of surface area of the slide $\left(\mathrm{mg}_{\text {biofilm }} / \mathrm{cm}^{2}\right)$.

The percentage of the biofilm removal was determined through the equation:

Biofilm removal $(\%)=\left[\left(W-W_{\mathrm{B}}\right) / W\right] \times 100$,

where $W$ is the biofilm mass without surfactant application $\left(\mathrm{mg}_{\text {biofilm }} / \mathrm{cm}^{2}\right.$ ) and $W_{\mathrm{B}}$ is the biofilm mass after CTAB treatment $\left(\mathrm{mg}_{\text {biofilm }} / \mathrm{cm}^{2}\right)$.

\subsection{Analytical methods-respiratory activity assessment}

The respiratory activity of the several samples was evaluated by measuring the oxygen uptake rate needed to oxidize glucose in a biological oxygen monitor (Yellow Springs Instruments BOM Model 53) according to Simões et al. (2003b).

The decrease in bacterial activity obtained due to the application of CTAB to both bacterial biofilms and suspended cultures of $P$. fluorescens was determined as the difference between the respiratory activities of the samples before (control) and immediately after the treatment with $\mathrm{CTAB}$, and expressed as the percentage of inactivation according to the equation:

Inactivation $(\%)=\left[\left(A_{0}-A_{1}\right) / A_{0}\right] \times 100$,

where $A_{0}$ is the respiratory activity of the control assay, i.e., without CTAB treatment ( $\mathrm{mg} \mathrm{O}_{2} / \mathrm{g}_{\text {biofilm }} \mathrm{min}$ ), and $A_{1}$ is the respiratory activity immediately after the application of CTAB (mg $\left.\mathrm{O}_{2} / \mathrm{g}_{\text {biofilm }} \mathrm{min}\right)$.

The same approach was used when BSA was added to the suspended bacterial cultures. In this case, the cultures of the control assays also include $3 \mathrm{~g} / 1$ of the protein.

All the respirometric tests were carried out at least three times for each condition tested.

\subsection{Analytical methods-ATP measurement}

The ATP released from the cells was measured with the luciferase-luciferine System /Sigma FL-AAM. After the contact time with CTAB, $100 \mu \mathrm{l}$ of the cellular suspension was added to $100 \mu \mathrm{l}$ of a 25 -fold dilution mixture of luciferine and luciferase. The light transmission was measured in a bioluminometer (Lumac, Biocounter $M$ 25000) and the output values were recorded in relative light units (RLU). Control experiments were made with PB in the presence and absence of BSA with the different CTAB concentrations to determine the interference of the protein and surfactant with the method. The effect of CTAB on the bacteria, evaluated in terms of relative light units as an estimative of the intracellular ATP content released, was calculated according to Dalzell and Christofi (2002), using the equation

Relative light units $=\left(\mathrm{RLU}_{1} / \mathrm{RLU}_{0}\right)$,

where $\mathrm{RLU}_{0}$ is the relative light units of the control assay (bacteria without CTAB addition, the control was different if in the presence or absence of BSA) and $\mathrm{RLU}_{1}$ is the relative light units of the test sample.

\subsection{Physical stability of the biofilm}

The physical stability of the biofilms was assessed by means of determining the biomass loss due to the 
exposure of biofilms to increasing rotating speeds in a rotating device, kept in a 3.51 reactor containing three suspended and immersed SS cylinders under rotation. This device was previously used to evaluate the physical stability of biofilms with and without biocide (Simões et al., 2003a). Biofilms were developed on three ASI 316 SS cylinders (surface area $=34.6 \mathrm{~cm}^{2}$ ), which rotate at $300 \mathrm{rpm}$, inserted in a 3.51 reactor, operating under the same conditions as the flow cells. After $7 \mathrm{~d}$ of operation, the cylinders covered with biofilm were carefully removed from the reactor. One of the cylinders was immersed in a reactor with $\mathrm{PB}(\mathrm{pH} 7)$, while the others were immersed, during $30 \mathrm{~min}$, in reactors each containing the different CTAB solutions (reactor volu$\mathrm{me}=170 \mathrm{ml}$ ). The exposure to the surfactant was also carried out with the cylinders rotating at $300 \mathrm{rpm}$. Immediately after the treatment, each cylinder was removed from the CTAB solution, accurately weighed, re-introduced in the reactor, now filled with $\mathrm{PB}$, and subjected consecutively to serial velocities of rotation, i.e., 500, 1000, 1500, and $2000 \mathrm{rpm}$, for a period of $30 \mathrm{~s}$ for each rotation. The experiments were repeated in three different occasions for every surfactant concentration tested.

The quantification of the final wet mass of the biofilm remaining attached to each cylinder, after submission to all the rotation speeds, was measured as the difference between the combined weight of the cylinder plus biofilm and the respective weight of the clean cylinder obtained before its introduction in to the 3.51 reactor. The same procedure was followed with the control assay, i.e., with the cylinder plus biofilm immersed in the buffer solution.

The wet mass of the biofilm remaining adhered to the surface area of each cylinder, after exposure to the full series of rotation speed, was expressed as percentage of biofilm remaining, according to the equation

$$
\begin{aligned}
& \text { Biofilm remaining }(\%) \\
& \quad=\left(W_{\mathrm{TSR}}-W_{\mathrm{C}}\right) /\left(W_{\mathrm{AT}}-W_{\mathrm{C}}\right) \times 100,
\end{aligned}
$$

where $W_{\mathrm{TSR}}$ is the biofilm mass plus cylinder after submission to the total series of rotation $(\mathrm{g}), W_{\mathrm{AT}}$ is the wet biofilm mass plus cylinder after CTAB treatment during $30 \mathrm{~min}(\mathrm{~g})$, and $W_{\mathrm{C}}$ is the wet mass of the clean cylinder, i.e., without biofilm adhered (g).

\subsection{Statistical analysis}

The data were analysed using the Statistical Package for the Social Sciences (SPSS). The mean and standard deviation (SD) within samples were calculated in all cases. The Student's $t$-test was performed when the aim was to investigate whether the differences between the experimental values obtained under different process conditions could be considered significant. Statistical calculations were based on confidence level equal or higher than $95 \%(P<0.05$ was considered statistically significant).

\section{Results}

\subsection{Tests with planktonic cells}

The effect of the surfactant on the bacterial cells was first investigated in planktonic tests (Fig. 1), by measuring the bacterial inactivation and the amount of ATP released. The possible interference of BSA with the antibacterial effect of CTAB was also assessed, by the addition of $3 \mathrm{~g} / \mathrm{l}$ of BSA to the bacterial cultures before CTAB treatment.

Fig. 1A shows that bacterial inactivation increases with CTAB concentration and that total bacterial inactivation was achieved for concentrations higher than $0.5 \mathrm{mM}$. However, the presence of BSA reduced significantly $(P<0.05)$ the antibacterial efficacy of CTAB. In fact, the ATP released to the medium increased as the CTAB concentration increased (Fig. 1B), suggesting that the surfactant promote a cellular disruption. Additionally, the presence of BSA has a protective effect against CTAB action, leading to the release of a lower ATP concentration $(P<0.05)$. A
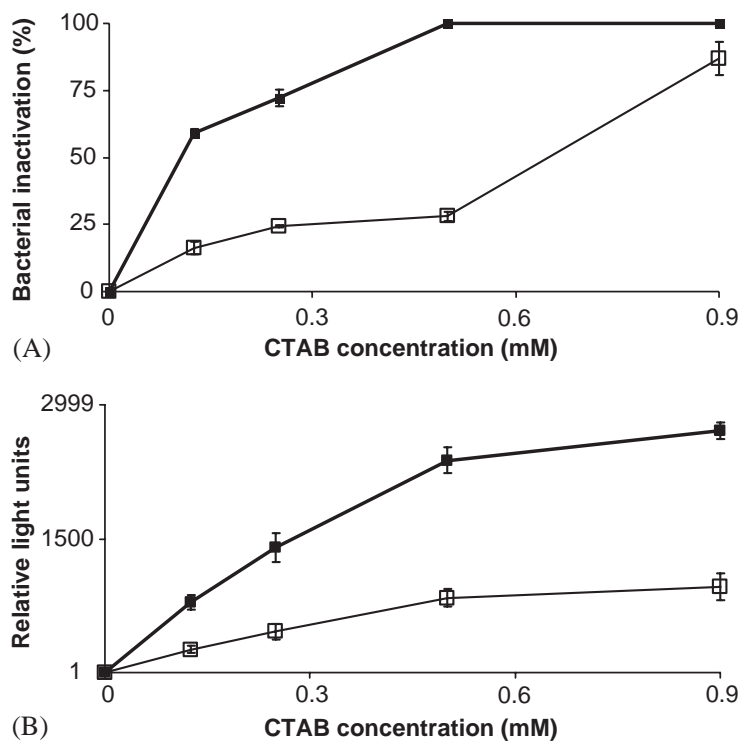

Fig. 1. Inactivation of the respiratory activity of the bacterial suspended cultures (A) after treatment with several concentrations of CTAB, with and without (control) BSA addition; relative light units as a measure of the ATP released from the bacterial cells (B) after treatment with several concentrations of CTAB. Each symbol indicates the means \pm SD of several independent experiments. - - - control; - $\square-$ with $3 \mathrm{~g} / 1$ BSA. 
strong relationship $\left(R^{2}=0.975\right)$ was found between bacterial inactivation and relative light units, meaning that an increase in inactivation corresponds to a proportional increase in the ATP released by the cells $(P>0.1)$. With BSA, a correlation coefficient of $R^{2}=0.602$ was found between bacterial inactivation and the ATP released. This latter relationship may indicate that when BSA was present in suspension, bacterial inactivation was related to the ATP released and probably, the cellular integrity was maintained in the presence of BSA.

\subsection{Evaluation of CTAB action on biofilms formed in the flow cells}

The effect of CTAB against biofilms formed under turbulent and laminar flow was assessed either by determining the respiratory activity and the variation of the mass of biofilm. Those results are presented in terms of percentage of biofilm inactivation and removal (Fig. 2) immediately after CTAB application. It should be noticed that the specific respiratory activity and mass of turbulent biofilms were much higher than laminar biofilms (Figs. 3-6). These figures show that for the control experiments, biofilms formed under turbulent flow were about five times more active and had about two times more mass than the ones formed under laminar flow. The application of CTAB to biofilms formed in the flow cells also resulted in an inactivation
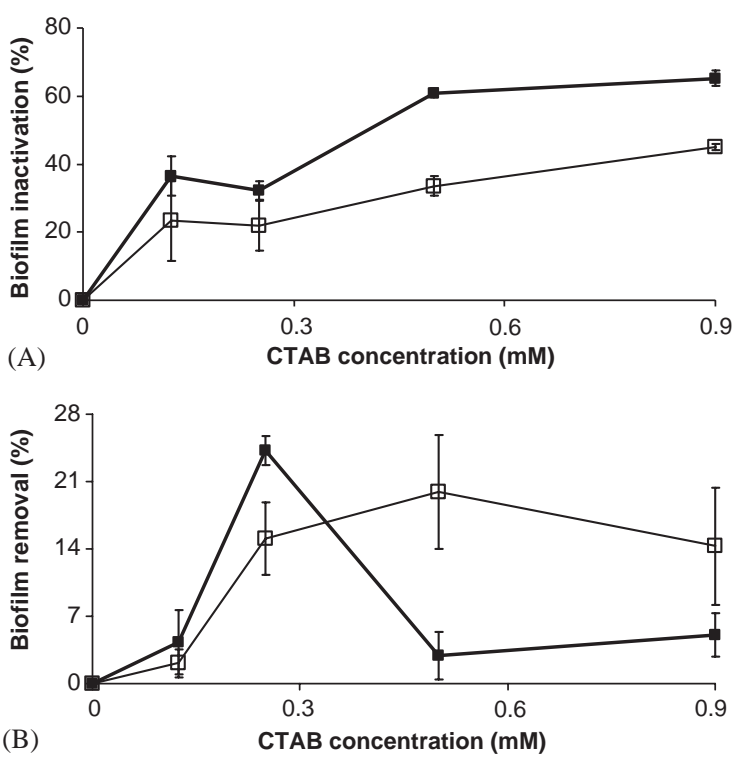

Fig. 2. Biofilms inactivation (A) and removal (B) due to application of different concentrations of CTAB. Each symbol indicates the means \pm SD of several independent experiments. $-\square$ - turbulent; - $\mathbf{\square}-$ laminar.

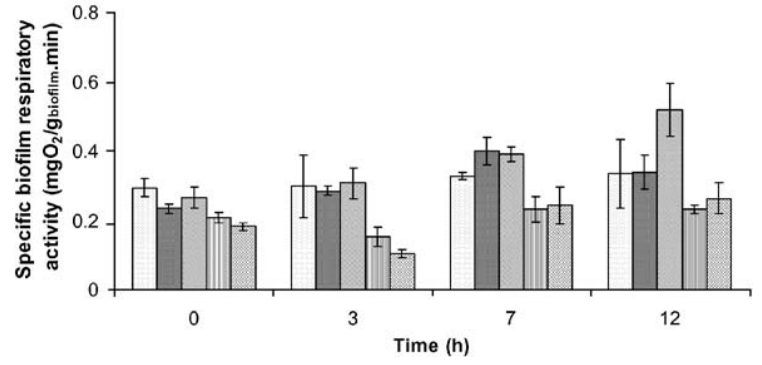

Fig. 3. Biofilm activity after CTAB treatment (0) and 3, 7 and $12 \mathrm{~h}$ later for turbulent flow. Each symbol indicates the means \pm SD of several independent experiments. Control means without $\mathrm{CTAB}$ application. - control; $\square 0.125 \mathrm{mM}$; $0.250 \mathrm{mM} ; \mathbb{\square} 0.500 \mathrm{mM} ; \square 0.900 \mathrm{mM}$.

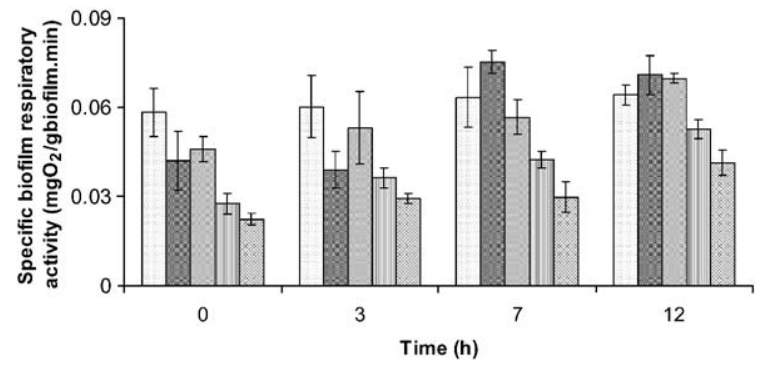

Fig. 4. Biofilm activity after CTAB treatment (0) and 3, 7 and $12 \mathrm{~h}$ later for laminar flow. Each symbol indicates the means \pm SD of several independent experiments. Control means without $\mathrm{CTAB}$ application. - control; $\square 0.125 \mathrm{mM}$; $0.250 \mathrm{mM} ; \mathbb{W} 0.500 \mathrm{mM} ; \square 0.900 \mathrm{mM}$.

of the bacteria within the biofilm, which increased with the increasing surfactant concentration (Fig. 2A). Concerning biofilms formed under different flow regimes, the inactivation effect was more pronounced in laminar biofilms than in turbulent biofilms $(P<0.05)$. Nevertheless, total biofilm inactivation was not achieved.

Concerning biofilm removal (Fig. 2B), CTAB had significant effect since the biofilm removal was always less than and close to $25 \%$ independent of the $\mathrm{CTAB}$ concentration. For laminar biofilms, more detachment was induced by a concentration of $0.250 \mathrm{mM}$, while for turbulent biofilms it was achieved only for $0.5 \mathrm{mM}$. Statistical comparison of the percentage of biofilm removal for turbulent and laminar biofilms showed that the results were similar $(P>0.1)$.

The results presented in Fig. 2A emphasized that after 30 min of CTAB treatment and for all the concentrations tested, biofilms still showed respiratory activity. In order to know whether this fact could lead to biofilm recovery, experiments were done in order to evaluate the post-surfactant effect. 


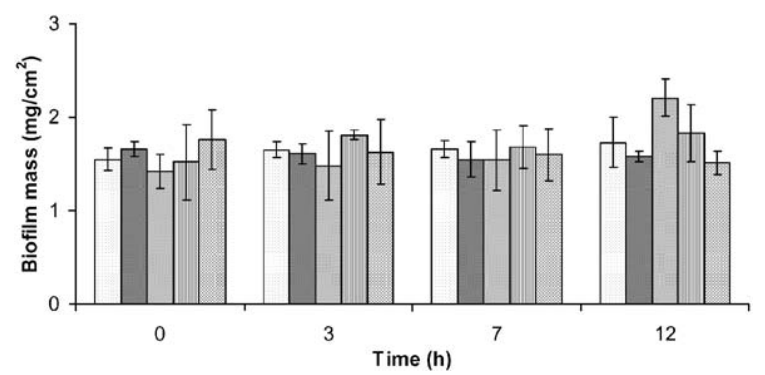

Fig. 5. Biofilm mass after CTAB treatment (0) and 3, 7 and $12 \mathrm{~h}$ later for turbulent flow. Each symbol indicates the means \pm SD of several independent experiments. Control means without CTAB application. - control; $\square 0.125 \mathrm{mM}$; $0.250 \mathrm{mM} ; \mathbb{m} 0.500 \mathrm{mM} ; \square 0.900 \mathrm{mM}$.

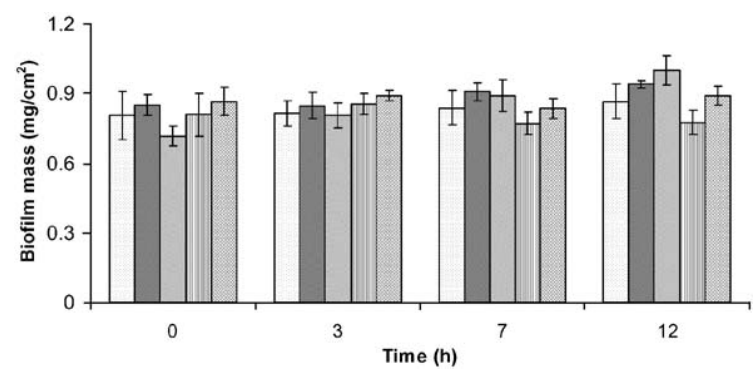

Fig. 6. Biofilm mass after CTAB treatment (0) and 3, 7 and $12 \mathrm{~h}$ later for laminar flow. Each symbol indicates the means \pm SD of several independent experiments. Control means without $\mathrm{CTAB}$ application. - control; $\square 0.125 \mathrm{mM}$; $0.250 \mathrm{mM} ; \mathbb{m} 0.500 \mathrm{mM} ; \square 0.900 \mathrm{mM}$.

\subsection{Evaluation of post-surfactant effect}

Figs. 3 and 4 present the post-surfactant effect on turbulent and laminar biofilms that remained on the metal surface, after surfactant application. That effect was evaluated in terms of respiratory activity after 3,7 and $12 \mathrm{~h}$ later and compared the results obtained after the immediate CTAB application (time zero).

As the remaining biofilm on the surface retained respiratory activity after $\mathrm{CTAB}$ application, it could be expected that the recovery of biofilms may occur if the initial conditions of the system were restored. In fact, for both biofilms submitted to CTAB treatment, there was a tendency of the biofilms to increase their respiratory activity. This trend is more pronounced with time and showed significant effects for biofilms treated with 0.5 and $0.9 \mathrm{mM} \quad(P<0.05$ - for both biofilms $)$ compared with the control experiment. The same tendency did not occur with the biofilm control (without CTAB application), since it did not show any variation of respiratory activity with increasing time for both biofilms tested as biofilms were at steady state (Pereira et al., 2002a).
Figs. 5 and 6 present the post-surfactant effect on turbulent and laminar biofilms evaluated in terms of biofilm mass remaining on the surface immediately after CTAB application (time zero), 3, 7 and $12 \mathrm{~h}$ later. From the results it is clear that the application of CTAB and the time did not promote any additional biofilm removal from the surface, for any conditions tested and for any sampling time $(P>0.05$ - for both conditions tested and for every concentration tested).

\subsection{Physical stability of biofilms formed on the rotating device}

The results of the physical stability of the biofilm after the surfactant treatment-which combine physical treatment after chemical treatment - expressed in terms of percentage of biofilm that remains adhered after a sequential exposure of the cylinders covered with biofilm to increasing rotation speeds, are presented in Fig. 7.

The change of the hydrodynamic conditions (due to the alteration of the rotation under which the biofilms were formed) promotes by itself a high biofilm removal $(75.6 \%)$. Nevertheless, the application of CTAB increases the amount of biofilm removal from the cylinders. The synergistic combination of higher surfactant concentrations and higher shear forces was the most efficacious means to promote biofilm detachment, since the application of CTAB seems to influence the physical stability of the biofilm. The amount of biofilm that remains adhered to the surface after $\mathrm{CTAB}$ treatment and exposure to the serial rotation speeds decreased with CTAB concentration $(P<0.05)$, for every condition tested, when compared with the control experiment and with the increase in the CTAB concentration. As an example, only $4.16 \%$ of the total biofilm remained attached to the cylinders after treatment with $0.9 \mathrm{mM}$ of CTAB and submission to the serial rotation speeds, while for the control experiment the percentage of biofilm that remains attached is $24.4 \%$, meaning that CTAB may have destabilized the structure of the biofilm.

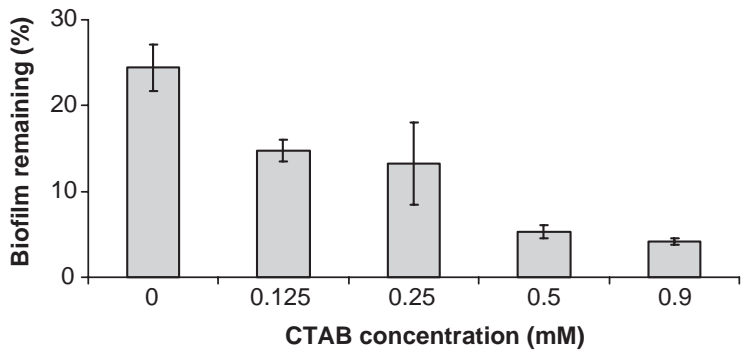

Fig. 7. Percentage of biofilm remaining after submitting the biofilm covered cylinders to different rotation speeds. Each symbol indicates the means $\pm \mathrm{SD}$ of several independent experiments. 


\section{Discussion}

The comparison of the results of Figs. 1 and 2, reinforced that the behaviour of bacterial cells exposed to a toxic environment was significantly different when the cells are in suspension or when they are embedded in a biofilm. This study showed the nearly universally observed resistance of biofilm microorganisms to disinfection when compared with their freely suspended counterparts. The results also underscore the inadequacy of planktonic testing methods for evaluating antimicrobial agents to be used as a means to control biofilms. According to Ishikawa et al. (2002), the surfactants may disturb membrane structure through interaction with cellular components, in particular proteins and lipids, being therefore used to extract proteins from cell membranes (Chatterjee et al., 2002). This fact can explain the diminished antibacterial effect of CTAB in the presence of proteins under dirty conditions (Fig. 1A) since the surfactant reacted with the BSA, and thus the amount of CTAB available for reaction with the cells was smaller. Similar results were previously obtained by Simões et al. $(2003 \mathrm{a}, \mathrm{b})$ on the decreased activity of non-oxidizing biocides in the presence of BSA.

The ATP bioluminescence assay used to evaluate the effect of CTAB on the bacterial cells showed that intracellular products were released when the cells were exposed to the surfactant. This result was not surprising, since QACs are believed to damage the outer membrane of Gram negative bacteria, thereby promoting the release of intracellular constituents (McDonnell and Russell, 1999). The results showed that BSA acted as a protective agent to the cells, avoiding their disruption, as presented in Fig. 1B.

The understanding of the effect of operational parameters that affect biofilm formation and subsequent disinfection plays a basic role on the establishment of a biofilm control program. Previous studies (Pereira et al., 2002b; Vieira et al., 1993), concerning the characterization of biofilms formed under turbulent and laminar flow, showed that turbulent biofilms are more active and have a higher content of proteins than laminar biofilms and that their physical structure is different. In the present study, the low efficacy of CTAB to control biofilms may be related with its chemical reaction with proteins of the exopolymeric matrix. This argument is reinforced by the tests with planktonic cells, which showed that the inactivation effect of CTAB was significantly reduced in the presence of BSA. The higher inactivation effect on laminar biofilms is probably related with the less amount of biofilm formed, compared with turbulent biofilms and, consequently, to the lower content of proteins (Simões et al., 2003a) which increases the CTAB available for reaction with the cells. In both hydro- dynamic situations, problems associated with mass transfer limitations within the biofilms can, always, decrease the action of CTAB.

The ability of CTAB to inactivate the biofilm was greater than its capacity to remove biofilms from surfaces, leaving biofilm on the surface not fully inactivated. Azeredo et al. (2003) have shown that CTAB $(0.5 \mathrm{mM})$ had the ability to cement bacteria to glass in spite of removing some of them. The survival of bacterial cells following CTAB treatment allowed the regeneration of the biofilm, allowing biofilm recovery. The preservative recovery showed by the post-surfactant effect evaluation could lead to populations of resistant bacteria, which may be recalcitrant to disinfection (Stewart, 2003). This potential of survival is remarkable, since the respiratory activity of the biofilms achieved, after $12 \mathrm{~h}$ in some experimental conditions, values higher than those observed without CTAB treatment. A more sustained antibacterial effect could be expected, since the biofilms which were not immediately sampled after CTAB application were not subjected to the CTAB neutralization step. Thus, the CTAB retained within the biofilm matrix had more chance to act on the bacteria. Forsythe and Hayes (1998) stated that surfaces treated with QACs could retain a bacteriostatic film due to the adsorption of the disinfectant on the surface. This film would prevent the subsequent growth of residual bacteria. Nevertheless, in this study it was proved that CTAB did not induce suppression of biofilm recovery for both biofilms (Figs. 3 and 4). The data also showed that the biofilm recovery was not only related to time, since for the control experiments, variation of the parameters analysed was not found with increasing time. Probably, the steady state of the biofilm was affected and biofilms recovered differently to a new steady state, depending on the concentration tested. The biofilm recovery must be associated with the stress conferred by the CTAB application. Probably, CTAB increased the availability of nutrients to the cells within the biofilms (promoting bacterial regrowth), since CTAB may have changed the structure of the biofilm matrix (demonstrated by SEM-data not shown), namely the porosity of the biofilm, and thus favouring the penetration of nutrients inside the matrix. According to Chandy and Angles (2001), one of the key factors that determine bacterial regrowth in drinking water distribution systems is the availability of nutrients.

Based on the physical stability results, the application of higher shear stress than the one under which the biofilms were formed promoted a high biofilm removal, as already pointed out by Vieira et al. (1993). Consequently, it is not surprising that the synergistic action of chemical treatment and mechanical cleaning in the efficient eradication of biofilms was observed, as shown in Fig. 7. Therefore, it can be said that CTAB promotes the instability of the biofilm. This fact may be related 
with CTAB ability to disrupt hydrophobic interactions involved in the cross-linking of the biofilm matrix (Chen and Stewart, 2000). However, even in this case, the permanence of a remaining pellicle that is still active, or in another metabolic state, may be a source of problems, such as biofilm regrowth, development of resistant biofilms or a harbour for other microorganisms.

The structure, composition and physiology of microbial biofilms have become inexorably linked with man's failure to control them by antibiotic and chemical treatments that are effective against suspended bacteria. This failure is related to the metabolic state of the bacteria of the biofilm, their extracellular products (exopolymers and extracellular enzymes) that moderates the access of the treatment agent and starves the more deeply placed cells (Gilbert et al., 2002) and the reaction of some components of the biofilm with the treatment products.

\section{Conclusions}

This study has implications in the understanding of the mode of action of CTAB and potential resistance parameters that can affect practical solutions for biofilm control. CTAB disinfectant effect is affected by the presence of proteins and promotes the release of ATP from the cells. Biofilms formed under laminar flow were more susceptible to inactivation than turbulent biofilms, but none of them were removed by the QAC. A postsurfactant effect was noticed for both biofilms since they recovered their metabolic activity with increasing time. The combined application of CTAB and subsequent biofilm exposure to higher shear stresses promoted increased biofilm removal, showing the synergistic effect of chemical and physical methods to control biofilms. This study emphasizes that organic fouling on the surface may also account for a diminished action of toxic agents.

\section{Acknowledgments}

The authors acknowledge the financial support provided by IBQF, and the Portuguese Foundation for Science and Technology (Project POCTI/1999/BIO/ 35683 and Ph.D. Grant-Manuel Simões).

\section{References}

APHA, AWWA, WPCF, 1989. In: Clesceri, L.S., Greenberg, A.E., Trussel, R.R. (Eds.), Standard Methods for the Examination of Water and Wastewater, 17th ed. American Public Health Association, Washington, D.C.
Azeredo, J., Pacheco, A.P., Lopes, I., Oliveira, R., Vieira, M.J., 2003. Monitoring cell detachment by surfactants in a parallel plate flow chamber. Water Sci. Technol. 47, 77-82.

Chandy, J.P., Angles, M.L., 2001. Determination of nutrients limiting biofilm formation and the subsequent impact disinfectant decay. Water Res. 35, 2677-2682.

Chatterjee, A., Moulik, S.P., Majhi, P.R., Sanyal, S.K., 2002. Studies on surfactant-biopolymer interaction. I. Microcalorimetric investigation on the interaction of cetylmethylammonium bromide (CTAB) and sodium dodecylsulfate (SDS) with gelatin (Gn), lysozyme (Lz) and deoxyribonucleic acid (DNA). Biophys. Chem. 98, 313-327.

Chen, X., Stewart, P.S., 2000. Biofilm removal caused by chemical treatments. Water Res. 34, 4229-4233.

Cloëte, T.E., Jacobs, L., Bröxel, V.S., 1997. The chemical control of biofouling in industrial water systems. Biodegradation 9, 23-37.

Dalzell, D.J.B., Christofi, N., 2002. An ATP luminescence method for direct toxicity assessment of pollutants impacting on the activated sewage sludge process. Water Res. 36, 1493-1502.

European Standard-EN 1276, 1997. Chemical disinfectants and antiseptics - quantitative suspension test for the evaluation of bactericidal activity of chemical disinfectants and antiseptics used in food, industrial, domestic, and institutional areas - test method and requirements (phase 2, step 1).

Forsythe, S.J., Hayes, P.R., 1998. Food Hygiene, Microbiology and HACCP, third ed. Aspen Publishers Inc., Gaithersburg, Maryland, pp. 327-371.

Gibson, H.J., Taylor, H., Hall, K.E., Holah, J.T., 1999. Effectiveness of cleaning techniques used in the food industry in terms of the removal of bacterial biofilms. J. Appl. Microbiol. 87, 41-48.

Gilbert, P., Allison, D.G., McBain, A.J., 2002. Biofilms in vitro and in vivo: do singular mechanisms influx cross-resistance? J. Appl. Microbiol. Symp. Suppl. 92, 98S-110S.

Ishikawa, S., Matsumura, Y., Yoshizako, F., Tsuchido, T., 2002. Characterisation of a cationic surfactant-resistant mutant isolated spontaneously from Escherichia coli. J. Appl. Microbiol. 92, 261-268.

McDonnell, G., Russell, A.D., 1999. Antiseptics and disinfectants: activity, action, and resistance. Clin. Microbiol. Rev. 12, 147-179.

Mereghetti, L., Quentin, R., Marquet-Van Der Mee, N., Audurier, A., 2000. Low sensitivity of Listeria monocytogenes to quaternary ammonium compounds. Appl. Environ. Microbiol. 66, 5083-5086.

Pereira, M.O., Vieira, M.J., 2001. Effects of the interactions between glutaraldehyde and the polymeric matrix on the efficacy of the biocide against Pseudomonas fluorescens biofilms. Biofouling 17, 93-101.

Pereira, M.O., Morin, P., Vieira, M.J., Melo, L.F., 2002a. A versatile reactor for continuous monitoring of biofilm properties in laboratory and industrial conditions. Lett. Appl. Microbiol. 34, 22-26.

Pereira, M.O., Kuehn, M., Wuertz, S., Neu, T., Melo, L., 2002b. Effect of flow regime on the architecture of a Pseudomonas fluorescens biofilm. Biotechnol. Bioeng. 78, 164-171. 
Simões, M., Pereira, M.O., Vieira, M.J., 2003a. Monitoring the effects of biocide treatment of Pseudomonas fluorescens formed under different flow regimes. Water Sci. Technol. 47, 217-223.

Simões, M., Carvalho, H., Pereira, M.O., Vieira, M.J., 2003 b. Studies on the behaviour of Pseudomonas fluorescens biofilms after ortho-phthalaldehyde treatment. Biofouling 19, 151-157.
Stewart, P.S., 2003. Multicellular nature of biofilm protection from antimicrobial agents. In: McBain, A., Allison, D., Brading, M., Rickard, A., Verran, J., Walker, J. (Eds.), Biofilm Communities: Order from Chaos. Bioline, Cardiff, pp. 181-190.

Vieira, M.J., Melo, L., Pinheiro, M.M., 1993. Biofilm formation: hydrodynamic effects on internal diffusion and structure. Biofouling 7, 67-80. 